\title{
El supermercado: un escenario de comercio para inventar el trabajo y el consumo
}

\author{
Felipe González Ortiz \\ Professor Doutor da Facultad de Ciencias Políticas y Sociales \\ da Universidad Autónoma del Estado de México
}

\begin{abstract}
Resumen Se hace el análisis del trabajo y el consumo en el supermercado, espacio o arena desde el que se configuran relaciones. A partir de las trayectorias de las mercancías y los trabajadores, se definen las formas económicas y culturales que configuran la oferta y la demanda. Se abordan las formas de segmentación de la oferta en función de la demanda, las formas de movilidad de mercancías en un sistema que se inscribe en lo global y lo local, y las maneras singulares de organizar las relaciones laborales para optimizar la misión de este tipo de comercio: realizar ventas al menudeo.
\end{abstract}

Palabras clave: supermercado, oferta y demanda, trayectorias de bienes, trayectoria de personal.

\section{Introducción}

Como parte del proyecto "Mercados de trabajo y consumo en las modalidades de comerciar" en el que participo, se presenta el presente artículo. Para dar contexto, señalamos que un grupo de investigadores iniciamos un proyecto en el que pretendemos comparar las distintas formas de mercadeo (acción de vender y comprar, para usar la frase que Appadurai propuso desde 1986) (Appadurai, 1991), es decir, se trata de abordar distintas arenas sociales y culturales en donde las mercancías se exponen para su realización comercial: estas arenas elegidas fueron el tianguis, el mercado fijo tradicional, ${ }^{1}$ el supermercado y las plazas de mercado de elite. Cada una de estas modalidades de comerciar representa escenarios desde los que se configuran estilos de oferta y demanda. Desde esta perspectiva, nos sumamos a la lógica de Appadurai cuando dice que las cosas iluminan el contexto social y humano (1991) en la medida que oferta y demanda configuran un ser social dado. Una serie de autores ilumina esta perspectiva que privilegia la dimensión social de las cosas o de los bienes, es decir, con el significado público que se comparte mediante la práctica de consumo en que los bienes se configuran como signos/significados (Douglas, 2008; Douglas; Isherwood, 1990). Ello ha dado entrada a la comprensión del consumo de cosas como la configuración de la personalidad por medio de la construcción de estilos visibles a través de cuadros de "refinamiento" culturalmente aceptados (Ewen, 1991).

Cada uno de estos contextos mercantiles conforma modelos culturales apropiables por consumidores que pertenecen a distintos estratos sociales, es decir, que desde sus formas sociales y culturales singulares

1. Tianguis es la forma de comerciar de manera itinerante, un día a la semana. El origen de esta forma de mercadeo se encuentra en los tiempos prehispánicos (Hirth, 2013). Mercado fijo tradicional se refiere al expendio de bienes ordenados en pasillos en los que cada puesto es propiedad de una familia. 
se constituyen en agencias para el encadenamiento de las cadenas de producción y consumo. De esta manera, los distintos contextos mercantiles que se analizan construyen tipos de sociedades, o lo que es lo mismo, la oferta y la demanda de bienes delinea las formas sociales en la medida de la interacción mercantil entre sociedad y mercancías, o sea, entre individuos pertenecientes a status y culturas específicas y significaciones cargadas en los bienes.

La clasificación de estos tipos de mercadeo es eminentemente empírica (la perspectiva es antropológica y, más aún, etnográfica), es decir, basta una mirada de reconocimiento a cada una de estas modalidades para darse cuenta de las categorías sociales (estratos) y culturales (étnicas) que asisten como oferentes y demandantes en estos escenarios. Dichas categorías impregnan las mercancías en tanto los contextos mercantiles son asuntos sociales. En este sentido, cada modalidad mercantil se entiende como un escenario en el que confluyen oferentes y demandantes de bienes y, en esa acción, se definen a sí mismos, pues resaltan sus formas culturales atravesadas por los orígenes étnicos y por las clases sociales. El universo de observación de este proyecto se circunscribe al valle de Toluca, es decir, a aquellos municipios que se despliegan, radialmente, desde el municipio de Toluca, pasando por la zona metropolitana y llegando hasta Atlacomulco en el norte de la entidad y a Tenango en el sur, a Zinacantepec en el poniente y a Huixquilucan y Tianguistenco en el oriente. ${ }^{2}$

Queda pendiente el análisis de las modalidades de mercadeo por internet que se están generando. Este artículo en particular aborda las maneras de organizar el comercio en la modalidad de mercadeo conocido como supermercado. Me refiero a aquellas que componen firmas comerciales tales La Comer, Soriana, Walmart, Chedrahui o Carrefour. ${ }^{3}$

Enfoco en las formas en que oferta y demanda se organizan para llevar a cabo la comercialización de los bienes. En este sentido, se parte de las trayectorias de las mercancías (Appadurai, 1991) y de las personas (Bueno, 2016). Ambas, mercancías y personas, se adscriben a sistemas de organización estructurados en función del objetivo que es vender bienes de consumo. En los contextos mercantiles se puede reunir a actores de muy distintos sistemas culturales, quienes comparten el mínimo entendimiento a que obliga el comercio o el acto de vender o comprar (Appadurai, 1991), pero se verá en el trabajo que la oferta de este tipo de firmas segmenta la demanda, generando así una especie de relación significante entre mercancía e individuos definible por los prestigios, los estilos y los refinamientos, todos aspectos simbólicos engarzados al consumo (Douglas, 2008; Ewen, 1991). El estudio de las distintas formas o contextos mercantiles nos ha llevado a considerar una distinción en la demanda final de los bienes. Ésta se compone por dos tipos: los usuarios y los consumidores (Alba, 1995). Mientras el usuario se aferra a la durabilidad de los objetos en la medida de su valor de uso, el consumidor se adscribe a una especie de ideología de la obsolescencia (Leonard, 2013) que lo lleva a cambiar permanentemente el bien o la mercancía; es decir, mientras el usuario se aferra al valor de uso, el consumidor lo hace al valor de cambio (Baudrillard, 1989), en la medida que cada bien es un significante perpetuo. Oferta y demanda son más que meros componentes formales de la economía, son partes sustantivas, en el sentido de la vieja hipótesis de Polanyi (1976) de la sociedad, pues dimensiones tales como la cultura o lo político (el mundo institucionalizado) intervienen en las configuraciones sociales en que la oferta y la demanda terminan decidiendo las formas de comprar y de vender.

En este sentido, desde la oferta se privilegia el concepto de trayectorias de los empleados para dar cuenta de las inserciones laborales en el sistema de mercado globalizado que se expresa en la modalidad de supermercado. De la misma forma, se estudia la trayectoria de las mercancías para dar cuenta de la organización y articulación del sistema económico (o los sistemas) que se inscriben en la lógica comercial de esta modalidad. Oferta y demanda influyen en la configuración de sociedades y en la intención de construir consumidores; esto se observa en la estrategia de la obsolescencia con la que están "sellados" los bienes que pasan por el código de barras, como veremos en el trabajo.

El análisis enfoca en el Walmart. ${ }^{4}$ Abordaré las formas de segmentación de la oferta en función de la demanda como una forma de construir sociedad, y las formas de movilidad de mercancías en un sistema que se inscribe entre lo global y lo local. Abordaré también las maneras singulares de organizar las relaciones laborales para optimizar la misión de este tipo de comercio: realizar ventas al menudeo. Esta firma es de las más globalizadas, es decir, actúa con estrategias de mercado agresivas capaces de movilizar productos de cualquier rincón del mundo para ponerlos en manos del consumidor más singular (Leonard, 2013), además de movilizar también poderes políticos

2. El valle de Toluca representa una zona metropolitana difusa de dos millones de habitantes ubicada a 70 kilómetros al poniente de la ciudad capital de México. Véase González Ortiz, 2012.

3. Modalidades del mismo tipo son Sams o Cotsco, sólo que éstas hacen ventas al mayoreo y se requiere de una membrecía.

4. Walmart cuenta con 11 mil tiendas en todo el mundo, de las cuales 3 mil se encuentran en México. Se trata de una firma transnacional cuyo origen se remonta a 1962, cuando Sam Walton inició esta empresa en Arkansas. (Disponible en: <http://www.bbc.com/mundo/ noticias/2016/01/160115_economia_walmart_cierre_tiendas_estados_unidos_mundial_ppb>. Acceso en: 16 jun. 2017. 
para conseguir, por cualquier medio, la localización y ubicación de sus tiendas (Raphael, 2014). ${ }^{5}$ De esta forma, el carácter global de esta empresa puede caracterizarse por su fortaleza para movilizar bienes de mercado y voluntades políticas.

El método utilizado se sustentó en entrevistas a profundidad a oferentes y demandantes de los bienes de este supermercado. Las entrevistas se estructuraron de forma semiabierta con un guión que abarcaba dos rubros: la trayectoria de las mercancías y la de los empleados. ${ }^{6}$

\section{Trayectoria de las mercancías o la diversidad de mercancías y encadenamiento de economías locales y globales}

Entrar en una tienda Walmart Supercenter da la sensación de que nos sumergimos en un universo "chispeante" en que las mercancías nos guiñan, clamorosas, necias y hasta con desesperación, ${ }^{7}$ para que las adquiramos. Se trata de un universo en el que la compra se convierte en el imperativo conductual que puede rayar en la obsesión. El consumidor queda atrapado en un mundo de bienes dispuestos en una estética ordenada de saturado inventario singular. Es como si el mensaje fuera "de una entrada puedes comprarlo todo".

El orden de las mercancías representa una fachada que esconde al consumidor el sistema económico que se encuentra detrás de este contexto mercantil. Si con el tianguis es fácil observar la conexión entre productor, intermediario y consumidor (lo mismo en el mercado fijo tradicional), en el supermercado el sistema económico en su conjunto queda invisible a los ojos del consumidor; hay una malla mental en la que el sistema de producción consumo queda invisibilizado (Leonard, 2013), pues las mercancías o bienes simplemente están allí, "relucientes" y dispuestas a nuestra elección. Este fetichismo se expresa no solamente en que en cada bien se enajena la explotación del trabajo, como decía Marx (1986), sino también en el hecho de que el conjunto más variado de ellas, aglutinadas en un solo lugar, produce un velo que termina por cegar el proceso productivo en su conjunto. Si en los centros comerciales de elite la visibilización de los bienes se erige a través de la espectacularidad publicitaria de la marca que asigna status y prestigios a los potenciales consumidores mantenidos en estado mental infantilizado, según dice Barber (2008), en los supermercados la visibilización se establece a través del aglutinamiento que da la sensación de "querer comprar todo a la vez", de acceder a la totalidad de bienes. Se establece así una sensación de suficiencia y acceso al mercado plural: "Todos los bienes al alcance la mano". De esta forma, la sensación de acceso a los bienes globales en tiempo real representa la experiencia del consumidor en un universo puesto (dispuesto) para él.

En cualquier Walmart Supercenter es común observar actividades económicas, financieras y culturales a la vez. No obstante, la misión central son las ventas. En este objetivo se proyecta la dimensión económica de este tipo de mercadeo, pues se trata de un centro económico de escala que relaciona directa e indirectamente a productores globales y locales para su distribución comercial. Pero también se desarrollan las actividades financieras mediante las tarjetas de crédito que la firma oferta; de ahí que otra función global se inserta en su funcionamiento, en la medida que la especulación de mercancías futuras y deuda entran en el juego de esta modalidad de mercadeo a través de la promoción de niveles de endeudamiento. En el rubro cultural, por otro lado, se establece la proyección de la firma como una empresa de prestigio. Mediante un sistema de comunicación se resaltan las formas singulares de ser, mecanismo de producción de la imagen corporativa y el despliegue de una serie de dispositivos para crear una cultura e identidad para los que pertenecen a la firma empresarial (trabajadores). En este sentido, en esta empresa se juntan las actividades económicas que se refieren a las formas estructurales de articulación de bienes globales y locales, la dimensión financiera que trabaja con el crédito y la deuda, y la cultural, que construye una imagen corporativa con insumos culturales de pertenencia.

Los bienes que se expenden en una tienda de este tipo de mercadeo son plurales. Esta pluralidad establece relaciones diversas con el tipo de proveedor.

\footnotetext{
5. Es conocido el escándalo de corrupción del que fue objeto esta firma en la ocasión de su localización en México. Disponible en: <http:// www.elfinanciero.com.mx/empresas/escandalo-por-sobornos-de-walmart-con-pocas-evidencias-de-corrupcion-wsj.html> y <http://expansion. mx/negocios/2013/04/17/walmart-el-costo-a-un-ano-del-escandalo>. Acceso en: 16 jun. 2017.

6. Se realizaron tres entrevistas (una mujer y dos hombres) a personas que trabajaron como subgerentes en la firma Walmart. Estas entrevistas se realizaron en los meses de agosto y septiembre del año 2016. En lo que respecta al consumidor, las entrevistas se complementaron con observaciones de campo y, en la medida que se hicieron in situ, fueron más ágiles y cortas pero proporcionaron suficientemente la idea del perfil de esta demanda.

7. Ello es distinto de la modalidad de mercadeo de elite, donde las mercancías nos guiñan el ojo de manera seductora y persuasiva, invitándonos a formar parte de un grupo de elite mediante la compra de un bien de marca.
} 
Si se trata de bienes agrícolas o perecederos, el nivel de surtimiento y acopio es distinto que el de bienes mecánicos, abarrotes, ${ }^{8}$ ropa, blancos, herramientas, farmacia, belleza, pinturas u hogar. De esta manera, es imposible llevar un sistema automatizado para la totalidad de bienes, que es la meta ideal del sistema de venta de este tipo de mercado. Y es que el modo organizativo de las ventas se orienta en un sistema automatizado que comienza en los códigos de barras y en las cajas. De éstas, pasa la información de ventas al Centro de Ubicación, lugar en el que se tiene el control de entradas, salidas y merma. ${ }^{9}$ Una vez que la cantidad de bienes se reduce (menos de tres unidades por bien, por ejemplo), el Centro resurte el bien. Si se trata de un bien perecedero (de economía local o regional), como frutas y verduras, por ejemplo, el surtimiento se hace de dos a tres veces a la semana, pero si se trata de un bien de otra naturaleza (de economía global), el resurtimiento se hace bajo un esquema sin inventarios (lo que implica no contar con bodegas o almacenes). Se trata, en este tipo de mercancías, de un sistema más cercano al toyotismo que funda su funcionamiento no en los inventarios sino en los requerimientos específicos del consumo, es decir, en la demanda puntual de un bien singular (Bell, 2007; Bauman, 2000; Bueno, 2016; Harvey, 2005; Castells, 2006).

Pero no sucede así con la totalidad de mercancías, pues cada una de ellas tiene su propia trayectoria que la conecta con la producción, la comercialización y el consumo. Por ejemplo, el caso de las tortillas ${ }^{10}$ y el pan; funcionan ambos bajo un esquema fordista en que la fábrica se hace cargo de la totalidad del producto, es decir, se incorporan en una sola actividad la producción, la comercialización y el consumo. En este tipo de mercancías el proceso de realización implica la totalidad de la trayectoria del bien. Hornos y la máquina de hacer tortillas (medios de producción) se encuentran vinculados con el producto final y su realización comercial, para pasar a manos del consumidor. En esa medida puede considerarse un bien producido bajo el modelo fordista, existente al interior del Walmart o de este tipo de mercadeo. La trama de mantener estos bienes, además de los perecederos como frutas y verduras, es precisamente la de mostrar la oferta plural, el aglutinamiento de bienes como lo más característico de este tipo de escenarios de mercadeo, lo que significa también, como dije antes, persuadir al cliente para que lleve la totalidad de bienes, considerados necesarios, al hogar, al consumo. Sucede así que, cuando la maquinaria (tortilladora y hornos) se descomponen, pueden pasar varios días (semanas y a veces meses) sin compostura, pues las ventas de estos bienes "no hacen la diferencia en las ganancias de la tienda". Cuando sucede esto, no significa que se dejan de vender dichos bienes en tal tienda supercenter, sólo significa que el bien se compra en otras tiendas, supercenter también, y se revende en la primera.

De ahí que algunos bienes, argumentan los entrevistados, funcionen "como ganchos", es decir, como "carnada" para atraer a la demanda, entre ellos las frutas, las verduras, las tortillas y el pan, todos ellos perecederos. Estos productos no dan ganancia, dicen, pero su contribución consiste en representar bienes "gancho" para atraer a los consumidores y no disminuir la imagen de que en este tipo de mercados se encuentra la totalidad de bienes necesarios y, también, de los existentes en el mundo.

Sobre las frutas y legumbres: La compra de estos bienes se hace a intermediarios que compran a los campesinos. Aquí hay una articulación interesante de economías. Un requisito indispensable de quien vende las mercancías a Walmart es que esté dado de alta en Hacienda, lo que excluye a la totalidad de la economía campesina de esta interacción, pero potencia al intermediario. De esta forma, las mercancías pasan de sistemas locales de producción a este supermercado cuando de productos como frutas y legumbres se trata. Estos bienes se consideran "ganchos" para atraer al consumidor, "bienes que no aportan ganancias significativas pero si atraen el consumo" expresado en la demanda. Estos bienes, las frutas, legumbres, tortillas y pan, se puede decir, forman parte de aquellos productos de economías campesinas ${ }^{11}$ y del tipo fordis-

\section{Los abarrotes son generalmente bienes empacados o enlatados.}

9. La merma es el producto que se pierde de los controles de entradas y salidas. Llega el producto, se descarga, allí se genera cierta cantidad de merma, luego al traslado a piso. Una forma de controlar la merma es el inventario diario; un bien puede no estar en su lugar pero a la vez no existir registro de su venta en cajas; seguro que se trata de un producto que se lo llevó el cliente y lo dejó en otro lugar o de un robo. Por lo regular este bien se pierde. De esta forma, la merma se administra. Se parte de un promedio de merma. El robo es otra modalidad de merma; es el área de prevención de ventas la que se encarga del robo. Todo lo que no sea venta es merma. Lo que no se vendió es merma.

10. Las tortillas se hacen de maíz molido y son un alimento típico de la dieta mexicana.

11. Algunas tiendas de este tipo se engarzan con economías locales artesanales; es el caso de La Comer, ubicada en el municipio de Atlacomulco, la zona mazahua al norte del valle de Toluca, que adquiere a consignación estropajos y fibras que elaboran en algunas comunidades indígenas de la zona. En una entrevista a un artesano de estropajos, él manifestaba con gran orgullo que su producto ya se expendía en La Comer, lo que le hacía sentir que estaba transitando de simple comerciante a empresario. Esta ideación de sí mismo es muy interesante porque muestra como los centros comerciales asignan status diferentes a los proveedores, lo que indica la preeminencia ideológica del capitalismo moderno (fordista) y posmoderno (toyotista) frente a formas premodernas de producción distribución consumo. Lo mismo sucede con algunos productos que algunos restaurantes, como el Toks, hacen al comprar moles y mermeladas a mujeres de comunidades mazahuas. No obstante, este tipo de encadenamientos económicos no se ha generalizado y, me parece, son una veta de investigación importante. 
ta respectivamente. Pero existen los otros bienes, los que se insertan más bien en la lógica del toyotismo, es decir, que se mueven en función de la demanda puntual, se trata de los bienes no perecederos, aquellos que entran en inventarios automatizados con códigos electrónicos e información puntual. Este tipo de bienes se adquiere en función de la demanda y no se almacena en inventarios de bodegas o almacenes, sino que su control se hace desde un Centro de Ubicación al cual llega la información automatizada de las ventas por bien individual. De esta forma se hacen los pedidos de forma unitaria, bajo el esquema del toyotismo. Se puede ver, así, que se trata de una suerte de escenario de mercadeo que combina los modelos fordistas y toyotistas en las formas de expender los bienes. Es importante decir que la ideología de la obsolescencia se encuentra en los bienes automatizados; en todos ellos hay leyendas que indican un límite de consumo, lo que persuade y tensa a la demanda entre adscribirse por ser un usuario o pasar a ser un consumidor.

Así, afirmo que este contexto mercantil proyecta una modalidad de mercadeo que articula formas económicas premodernas (al conectar al intermediario con la economía campesina); formas modernas del tipo fordista (al contener el proceso productivo del bien en su totalidad, como es el caso de la tortilla y el pan) y formas posmodernas (como son la automatización del bien que se resurte en función de la puntual demanda, lo que se llama el toyotismo). Se "sacrifican" ganancias en los productos premodernos y fordistas, para atraer al consumidor que es persuadido por "el clamor desesperado" que los bienes automatizados lanzan, mediante su aglutinamiento pasivo, para ser comprados.

\section{La segmentación de la demanda como estrategia de mercadeo}

Recuerde el lector que considero la articulación entre oferta y demanda con un contenido institucionalizado, es decir, oferta y demanda terminan por contribuir a la estructuración de la sociedad en la medida que los bienes representan formas sociales en la proporción en que son socializadas. Este subapartado refiere, así, a las formas de estructurar al consumidor por parte de este tipo de emprendedurismo comercial cuyo escenario es el supermercado. El típico consumidor de esta modalidad de comercio es general. En él confluyen distintos tipos culturales extendidos al conjunto de los estratos sociales. Sin embargo, es dable ver, al menos en México, que la firma distingue consumidores según niveles de poder adquisitivo, pues los Walmart (Supercenter), los Bodega Aurrera y los Súper Compras forman parte de la firma. Se trata de una segmentación de la oferta en función de la demanda diferenciada por su nivel económico y estatus social. En esta medida la propia firma construye contextos mercantiles para distintos estratos sociales. Los Súper Compras se ubican en vecindarios adinerados, mientras los Bodega Aurerra en zonas pobres. Pero aun más, según las observaciones de campo que he realizado bajo la perspectiva que este proyecto, he visto que allí donde hay un tianguis, se coloca un Bodega Aurrera (el caso de Ocoyoacac e Ixtlahuaca); allí donde hay un mercado fijo de tradición, se coloca ya sea un Bodega Aurrera (el caso de Zinacantepec) o un Supercenter Walmart (el caso del mercado Juárez en Toluca). ${ }^{12}$ La instalación de estos contextos mercantiles se hace para competir con las otras modalidades (tianguis y mercado tradicional fijo). Hay en las estrategias de localización, desde mi punto de vista, una declarada disputa por la demanda. Se trata de una estrategia de campo de guerra (González Rodríguez, 2014) en la que se busca "atrapar" al consumidor (desplazando la competencia), adecuándose a su perfil estamental (entendiendo por estamento a un estrato social definido por características socioeconómicas y culturales), pero orientando y diseñando su gusto paulatina y pedagógicamente hacia una sola opción (escenario) de compra: el supermercado. En esta misma idea de comportamientos estratégicos para abordar nuevos mercados, dice Annie Leonard, que "cuando Walmart abre nuevos locales en nuevos mercados, ofrece descuentos considerables con el fin de sofocar a la competencia, y luego sube los precios cuando ya no quedan otros lugares donde comprar" (2013, p. 178). Puede ser, sería una estrategia lógica, típica y propia de una empresa transnacional, pero para el caso de México parece que no es una afirmación comprobable, al menos los informantes manifestaron que esta hipótesis no es aplicable a México.

Ahora bien, ¿por qué diferenciar o estamentar la demanda? La estrategia de la firma parece muy eficaz si consideramos el éxito que tanto Bodega Aurrera y Súper Compras tienen. No obstante, se debe reconocer que los barrios en los que se asientan no representan sino las formas singulares de ser de la sociedad mexicana, es decir, el territorio tiene las marcas de la jerárquica estructura social en su conjunto, altamente desigual y con una propensión cultural a desplegar dispositivos para marcar la diferencia como desigualdad ${ }^{13}$ (lo que se traduce en trampas sociales que terminan por perpetuar

\section{Todos estos municipios forman parte del valle de Toluca.}

13. Expresiones culturales que parecen frívolas y se usan en la cotidianidad pero que en realidad sustentan el bagaje discriminatorio con el que se establecen las relaciones sociales. Una reflexión interesante al respecto puede verse en el estudio de las relaciones interétnicas de Navarrete (2004) y en el sugerente estudio de Coronado (2003). 
la desigualdad, como dice Steward [2010]). Es decir, en el territorio se expresan las diferencias de estrato y clase social. Esta hipótesis ha sido tratada de manera exhaustiva por los estudiosos de lo urbano cuando muestran las fronteras territoriales como fronteras sociales, más específicamente entre fronteras sociales, políticas, culturales y económicas (Davis, 1992; Mckenzie, 1994; Blakeli; Gail, 1997; Soja, 1996, 2000; Caldeira, 2000; González Ortiz, 2009). Ello es una muestra social del mismo tema de desigualdad, que empieza a generarse en los estudios sobre la desigualdad horizontal, o la democracia con desigualdad, como formas culturales y políticas de crear y perpetuar la desigualdad (Steward, 2010; González; Valencia, 2017; Raphael, 2014). De esta forma, territorio y desigualdad son componentes articulados que explican las formas jerárquicas de la estructura social, situación empíricamente visible para cualquier firma extranjera que invierte en México. Así, se puede concluir, que el criollismo se ha convertido en la ideología que ha perpetuado la desigualdad en este país, una ideología colonial que seguimos cargando y que nos hace pensar en la actualidad de la vieja tesis, escrita desde 1963 por González Casanova, sobre el colonialismo interno (2009).

No obstante, la estructura de Walmart es grande, tanto que tienen una oficina de investigación en que la mercadotecnia es la fuente de las decisiones de localización de las posibles nuevas tiendas en los tres formatos descritos. De esta forma, la decisión de qué tipo de formato de tienda construir en tal territorio, y esto pese a que los estratos tienen empíricamente visibilidad territorial en México, se encuentra legitimada por la oficina de investigación en mercadotecnia con que cuenta esta firma comercial.

Así, dos de los tres formatos, Bodega Aurrera y Súper Compras, separan dos niveles de consumo, el bajo y el alto, mientras que Walmart supercenter se pretende totalizador, una opción para todos los estratos sociales, más democrático y más abarcador. De esta manera, tiene más variedad de productos en la medida que prescinde de los bienes exclusivos para los estratos bajos (hojas para envolver tamales, distintos tipos de chiles y plantas de olor para los alimentos, por ejemplo) y los de los estratos altos (vinos de importación, semillas y pasas, chocolates y variedades de quesos o jamón serrano, por ejemplo). Los supercenter Walmart expenden similares productos, aquellos que se consideran necesarios. ${ }^{14}$

De la misma manera, la competencia que realiza Walmart se puede clasificar en dos vertientes: 1) contra otras firmas del "mismo peso" como La Comer, Soriana y Chedrahui y 2) contra otras modalidades de mercadeo, como son los tianguis y los mercados fijos. Una manera de enfrentar la competencia entre los establecimientos del mismo tipo es mediante la exaltación de la excelencia. Entre las acciones para el logro y realización de ella se encuentran la limpieza de la tienda y los manuales de excelencia. Las comparaciones con otros centros comerciales siempre son un recurso que se utiliza para lograr la excelencia. "Un Soriana o un Carrefour siempre tienen sucio el piso", es una letanía que los trabajadores de Walmart pregonan, de ahí que un Walmart siempre pule el piso. Esta metáfora es interesante en la medida que el brillo proyecta la excelencia o, lo que es lo mismo, "la excelencia brilla", y esto se puede constatar en el piso pulido.

Ahora bien, la competencia con las otras modalidades de mercadeo. Cuando se trata de competir con un tianguis la estrategia es clara: Bodega Aurrera se presenta como el "contrincante del mismo peso". Entre las ventajas está el hecho de que se encuentra abierto todos los días, mientras el mercado tianguis solamente está un día a la semana, además de que los precios sean más baratos, en Bodega, que en el tianguis, e incluso que en el mercado fijo. De esta manera, el mensaje del supermercado puede ser: "De una entrada puedes comprar de todo"; mientras que el del tianguis es: "En un día de la semana puedes comprar lo de toda la semana"; y el del mercado fijo puede ser de naturaleza reiterativa al quedar de la siguiente manera: "Puedes comprar al menudeo, aquí estamos todos los días para que compres todos los días". Los mensajes son diferentes y compiten entre sí. De esta forma la oferta proporciona elementos para pensar en la sociedad, pero hay un aspecto más que el supermercado incorpora a la sociedad: se trata de una intención pedagógica, la de ir metiendo en la demanda la tensión angustiante de los tiempos de la obsolescencia de los bienes, es decir, la necesidad de consumir, y no de usar, los bienes que se adquieren.

\section{Trayectorias laborales de los trabajadores 0 asociados}

Una característica de Walmart es que "valora el salario para los profesionistas"(al menos en las entrevistas que realizamos encontramos esta afirmación), en el nivel de gerencias y subgerencias. La estimación consensuada es que los salarios son acordes con un recién egresado de carreras administrativas profesionales. El entrenamiento consta de tres meses "bien pagados considerando que eres un recién egresado" y

14. No obstante hay algunas excepciones, dicen los entrevistados: por ejemplo el supercenter de Jesús del Monte, en Huixquilucan, donde habitan comunidades judías que requieren de bienes más al perfil de su consumo cultural y de clase social, pues se trata de una sociedad de alto poder adquisitivo en la que incluso "son las sirvientas las que van a hacer el mandado", dicen los informantes. 
aumento salarial año con año. Se considera desde un principio que formar parte de esta firma es prestigioso y que por lo tanto "uno debe adecuarse a la forma como Walmart pretende perfilar a sus trabajadores". La estrategia de esta firma es interesante en la medida que recluta a los jóvenes recién egresados de las universidades para estos puestos de mando.

"El corporativo da un trato agradable y humanitario a las personas de recién ingreso", nos comentan los entrevistados, "te hacen sentir cómodo, los tratos son cordiales". Ante la pregunta sobre que puede existir una fama, de esta firma, por mal trato a sus empleados, todos responden con una contundente negativa, defienden los buenos tratos que les dieron, luego matizan al decir que Walmart tiene procedimientos que presionan a los trabajadores; dicha presión se observa de manera más nítida en las figuras de liderazgo (gerencias y subgerencias) y "es la presión a la que se encuentran sometidos lo que puede hacer explotar un mal trato". La presión se genera al desconcentrarse en las ventas; la tienda debe vender, esa es su misión. Esta misión impregna a todos, “desde las estructuras de mando, de las posiciones empresariales más altas hasta al jefe de piso", y cualquier asunto que distraiga ese objetivo se debe corregir de inmediato, ese es el imperativo. Pero al mismo tiempo la presión sobre "estas figuras de liderazgo" proviene de otra fuente, del trabajador mismo, pues "si uno de ellos siente que es maltratado, tiene una línea directa en la que se puede quejar". Entonces el corporativo investiga los hechos y castiga al gerente o subgerente si se comprueba el maltrato. "La línea directa es un teléfono que los asociados a Walmart pueden usar", y aquí hay otra cuestión: la de nombrar a los trabajadores como asociados. El término se ha normalizado tanto que nombrarlos trabajadores "se escucha raro"; ser asociados los coloca con otro status, una especie de socios, un mecanismo claro de pertenencia, de formar parte de una empresa, más que de una empresa de una meta; la de vender más.

A la vez, los procedimientos que se implementan con el personal son casi tan automatizados como los de las mercancías; por ejemplo, "no se despide a la gente a la primera, se hace un seguimiento, hay procesos de mejora en los que se habla con la gente y se le dan oportunidades de cambiar". Estos procesos de mejora son llamadas de atención, pero el nombre que se les da cambia el sentido de la amonestación; se trata de generar una oportunidad para cambiar, para mejorar; de esa forma se evita el disgusto y el rencor, la pulsión de venganza. A este procedimiento se le llama asesoría y en los términos de la interacción con el personal toma el nombre de "procesos de mejora", es decir, se enviste como una oportunidad para ser mejor, una apertura para transformar en buena la mala experiencia, una especie de pedagogía que "limpia" los ánimos que se despliegan inevitablemente en las relaciones laborales.

Cada Walmart tiene una estructura laboral que se replica a todas las tiendas. Primero el gerente, luego el subgerente, que se asigna en cantidad dependiendo del volumen de ventas de la tienda, que puede oscilar entre tres y cinco. Después, los jefes de departamento, ellos son los que se encargan del inventario diario de su departamento, cada uno se especializa en un bien en particular. Tras ellos, el supervisor, encargado de que los jefes de departamento hagan el inventario. El área de cajas es el siguiente puesto. Luego, al final de la estructura, los de limpieza. Están también los 1lamados cerillos, "todos ellos regulados aunque no son responsabilidad de la tienda". Ellos no pueden trabajar más de seis horas, deben estudiar y tener promedio de nueve y su actividad exclusiva es empacar, nada fuera de eso. Están también los "vieneviene", es decir, los encargados de cuidar los coches, pero ellos no dependen de la tienda; "el gerente tiene poder sobre ellos, él decide si se quedan o no". "En teoría ni cerillos ni los 'vieneviene' son asociados, pero su existencia en la tienda depende del gerente". De alguna manera, desde los asociados se tolera la informalidad, pero a la vez ellos no pueden hacer mucho, "aunque el gerente puede llamar a la policía y echar a los cuidadores de autos". El gerente es un puesto de poder y de prestigio. "Entre los asociados se valora mucho, se le respeta, es bien visto, admirado y se le sigue como a un líder". Incluso "en lugares donde el supercenter comparte espacio con otros establecimientos, el gerente puede decir a los establecimientos que limpien, si no le hacen caso, puede denunciarlos". En estos casos "siempre el Walmart tiene preferencia" y preeminencia frente a los otros establecimientos. De la misma forma "una subgerenta es vista con mucha equidad de género. A veces te ven raro por joven y mujer", dice una informante, pero la autoridad no disminuye por eso; "la empresa te respalda, basta que digas que hay que hacer algo y se hace".

"Organizarse para vender no es fácil”, comparten opinión los informantes, "y las presiones son muchas y constantes". Pero las relaciones sociales entre las jerarquías de los diferentes asociados se regulan por procesos. Todo tiende a estar automatizado. Por ejemplo, los "procesos de mejora" son consecuencia de relaciones que derivaron en mal entendidos. Si cuatro veces las mejores no hacen efecto en algún asociado, es causal de baja o de despido, "se desprende de la tienda, esa es la mecánica". A un asociado se le "desprende", no se le "despide" como a un trabajador; queda en el fondo de este testimonio esa lectura entre líneas. El "proceso de mejora" se encuentra dentro del procedimiento llamado "la asesoría". Ésta no es una llamada de atención ni un consejo imperativo, se trata de una asesoría pues a los asociados se les 
asesora no se les llama la atención; allí radica la lógica de este sistema de organización social para las ventas. Las relaciones sociales se fundan en esquemas que aparentan horizontalidad en las relaciones (un trato entre asociados) y la automatización juega un papel clave. Se trata de un emprendimiento de asociación de individuos, no de comunidades afectivas, se trata de una sociedad tipo Gelleschaft, para usar el viejo concepto de Tönnies (1979). De esta manera se establece un sistema de relaciones que aparenta neutralidad, que promueve aparentes relaciones horizontales en una estructura altamente vertical. El poder de la asociación radica en que cada quien cumple su rol de manera "silenciosa y acrítica" porque se sabe parte de una gran asociación.

Este tipo de estructuración de las relaciones sociales recuerda la vertiente funcionalista al estilo de Parsons (1961) y Merton (2002), ${ }^{15}$ pues los reconocimientos o el sistema de premios al trabajador se pueden testificar empíricamente, cada día, en las transmisiones permanentes que hace el canal de televisión de la tienda, pues en él se proyectan (además de las entrevistas con los directivos, actividades filantrópicas y altruistas que la firma hace por la sociedad) las historias de éxito de un gerente, un subgerente o cualquier asociado. De esta manera, el reconocimiento que la tienda le hace a sus asociados tiene una importancia capital en la medida que funda la pertenencia pero también porque se proyecta como un premio o recompensa por el buen desempeño del rol que le toca asumir en la estructura empresarial. En este sentido, el reconocimiento se convierte no en un asunto de cordialidad sino en una política de la empresa para mantener a los asociados en un nivel de tolerancia y satisfacción al rol desempeñado, al tiempo que se genera la pertenencia. ${ }^{16}$

Se tiene así que el rol de gerente es el puesto que cualquiera quisiera alcanzar. Da prestigio y da buena proyección en la trayectoria laboral del trabajador. Ser gerente de una Bodega Auerrera es de menor prestigio, lo es más de un Walmart supercenter o de un Súper Compras.

\section{Conclusiones}

He analizado el tema del trabajo y el consumo en la modalidad de mercadeo llamada supermercado. El universo de la reflexión partió de entrevistas a ex subgerentes del corporativo transnacional Walmart. Metodológicamente se hicieron tres entrevistas a personas que laboraron en dicha firma, especialmente en el puesto de la gerencia y la subgerencia. Las pláticas que tuvimos con ellos fueron estructuradas a partir de una guía de entrevista en que interesaba la trayectoria de las mercancías (producción, comercialización y consumo) y las trayectorias de las personas que laboran en dicha firma empresarial. Recuerde el lector que el objeto del proyecto de investigación del que se parte refiere a la configuración del trabajo y del consumo en diferentes modalidades o escenarios mercantiles, siendo el supermercado una de entre otras como son el tianguis, el mercado tradicional fijo y los centros comerciales de elite, faltando por investigar las centrales de abastos, el mercado en internet y las firmas comerciales con membrecía. ${ }^{17}$

El aspecto de las trayectorias del trabajo y los bienes (Bueno, 2016) se genera al considerar que las relaciones mercantiles son más que meras relaciones económicas para insertarse en entramados institucionales (Polanyi, 1976), en que los bienes son portadores de significados (Douglas, 2008; Ewen, 1991) y las mercancías muestran entramados sociales en tanto ellas son un asunto social (Appadurai, 1991). De ahí que en este trayecto del trabajo y el consumo en el contexto mercantil llamado supermercado es la tensión permanente entre la producción social de un usuario y de un consumidor. Esta tensión se visualiza en la existencia de bienes perecederos y bienes automatizados en los que se marca la obsolescencia, lo que transforma angustiantemente al usuario en consumidor obsesivo. La lógica del trabajo y del consumo se centra en la construcción de un consumidor permanente.

Otra conclusión afirma que se trata de una empresa transnacional que trabaja de forma diferenciada según el país en el que se inserta. De esta manera, en el análisis se observó que no se trata de una empresa que en todas partes establezca las mismas estrategias para acaparar (diseñar) al consumidor. En Estados Unidos es probable que cuando busca apropiarse de un mercado específico, baje los precios para después alzarlos (Leonard, 2013), pero en México la estrategia se da mediante el aprovechamiento de la segmentación de la sociedad, observable en el territorio, lo que genera el criterio para abrir distintos formatos de tienda según el poder adquisitivo de los vecindarios; Bodega Aurrera en zonas pobres, Súper Compras en zonas de alto poder adquisitivo y Walmart supercenter para todo tipo de estamento o categoría social.

15. Me refiero al planteamiento sobre rol, estructura y recompensas en el esquema parsoniano y al modelo de recompensas insatisfechas de Merton, escritas a mediados del siglo XX. Ver Parsons (1961) y Merton (2002).

16. El reconocimiento es un concepto propio de la sociología que ha calado de manera importante en los estudios conductuales y en los del multiculturalismo (Taylor, 1999). Parte del hecho de que todos necesitamos ser reconocidos en nuestro origen cultural y en nuestro desempeño social.

17. Pero también los mercados gourmet y ahora los mercados alternativos de productos orgánicos 
En cuanto a las mercancías, se observó que existen tres tipos que se adscriben respectivamente a tres modelos de economías; la premoderna, que pertenece al mundo de la economía campesina; la moderna en el estilo fordista, en que se mantiene la totalidad del proceso productivo del bien en cuestión; y la posmoderna, que refiere más al modelo del toyotismo, que se define por la demanda puntual y no por la de inventarios. Los bienes premodernos son las frutas y verduras; los modernos las tortillas y el pan y los posmodernos los demás bienes que pasan por un sistema automatizado de oferta y demanda puntual donde la información electrónica indica las entradas y salidas del bien. Esta diferenciación de los bienes los distingue como "mercancías gancho" y mercancías para la ganancia. Las primeras no suman significativamente a las ganancias de la tienda pero se mantiene su venta en la medida que operan como "carnada" para atraer al consumidor y estar acorde con el gusto local de la demanda. Estas mercancías son precisamente las que en el análisis detallo como premodernas y modernas del estilo fordista, es decir, las perecederas, las que se encuentran fuera del sistema automatizado de ventas. Por su parte, las mercancías automatizadas son las que generan las ganancias sustantivas para la tienda, pero su función más importante es su componente pedagógico al construir una demanda obstinada con la obsolescencia, lo que la convierte en consumidora y la trasciende de ser usuaria de bienes duraderos. Así, Walmart nos presenta un universo saturado de bienes. Su origen diverso nos hace suponer que asistimos a un escenario en que se encuentran los bienes de todo el mundo, incluidos los más locales y más idiosincráticos. El mensaje que da la disposición de las mercancías en los interiores es: "de una entrada se compra todo".

Regresando a los formatos de tiendas en función de las zonas definidas según el poder adquisitivo. El corporativo se erige como una competencia, en ciertos lugares, para otros contextos mercantiles, como son los mercados tianguis o los mercados tradicionales fijos, siempre bajo el objetivo de ir conformando una demanda acorde con el gusto hacia la oferta que el corporativo proporciona y con la pedagogía del consumo basado en la obsolescencia.

La articulación entre las trayectorias de los bienes y las trayectorias del trabajo es visible en la medida que la oferta intenta siempre construir la demanda en función de la ideología de la obsolescencia. Allí es donde se articulan. Pero en lo que respecta exclusivamente a las trayectorias laborales, es interesante que los entrevistados coinciden en que el corporativo representa una oportunidad para los recién egresados de carreras administrativas. El trato es considerado cordial pero la presión por el logro de la misión del corporativo, las ventas, representa una frágil frontera en las relaciones sociales, pues éstas se pueden desbalancear fácilmente hacia el maltrato. No obstante, dicen los entrevistados, los procesos de reconciliación son exitosos y eficaces, pues mantienen un sistema de neutralidad aparente dado por el hecho de que todos asumen el rol desempeñado en función del objetivo de la empresa. De esta manera, los trabajadores no son tratados como tales sino como asociados, lo cual genera un tipo de relaciones distintas, pues mantiene un halo de horizontalidad pese a la vertical estructura que organiza el trabajo; de la misma forma, los procedimientos de llamadas de atención al personal se definen de tal forma que generan un aura de poca verticalidad al llamarlas procesos de mejora.

El hecho de que los trabajadores sean nombrados asociados proyecta el compromiso con la tienda, pues todos hacen sociedad para lograr la misión en la medida de sentirse pertenecientes al corporativo. Las llamadas de atención se nombran asesorías, es decir, se "visten" de reuniones de consejos y pláticas cuya meta es hacer consciente al trabajador de su falta o falla. De la misma manera, las amonestaciones son nombradas "proceso de mejora", lo que significa que el asociado o trabajador se inserta en un procedimiento de reconocimiento de su falla o falta para tratar de mejorar. Esta mejora significa estar acorde con la misión de la empresa. Después de cuatro "procesos de mejora", el asociado puede ser desprendido de la empresa o, lo que es lo mismo, el trabajador puede ser despedido. A partir de las definiciones de los roles y los procedimientos para alinear al empleado con los objetivos de la empresa, se genera el aura de un tipo de organización social neutral. Los procedimientos son claros y específicos y cada uno de los trabajadores encuentra las ocasiones para desempeñar su rol, a la vez que encuentra las ocasiones para el reconocimiento por su labor desempeñada.

Los reconocimientos y premios al desempeño laboral proyectan el modelo de estructura funcionalista, muy socorrido en los Estados Unidos, donde el rol se desempeña satisfactoriamente siempre y cuando haya una serie de premios y reconocimientos que mantengan el acuerdo y el conformismo por parte de quien desempeña el rol. Para enfatizar esto, el corporativo cuenta con programas de televisión en que se muestran los casos de éxito, proyectando aspiraciones entre los asociados. Este modelo es tan exitoso que el prestigio asociado al gerente es muy valorado y se convierte en un antecedente positivo para el trabajador en su trayectoria curricular.

Por último, me parece que este tipo de establecimientos genera una idea colectiva de modernidad a la que todos aspiran entrar. Las modalidades de este mercado se encuentran entre las populares e idiosincráticas (tianguis y mercados fijos tradicionales) y las modernas (los centros de comercio de elite). El dise- 
ño de la demanda o del consumidor se encuentra en todos estos mercados pero es un hecho que este tipo de mercadeo lucha por acaparar a la totalidad de la demanda en la medida que le interesa construir consumidores (subsumidos en la lógica de la obsolescencia). Está en ella, en el consumidor, decidir el tipo de mercado de bienes al que quiere acceder, mientras el corporativo será paciente en la pedagogía implementada para diseñar el gusto de la demanda en cualquiera de sus formatos.

\section{Bibliografía}

ALBA RICO, Santiago. (Las reglas del caos. Apuntes para una antropología del mercado. Barcelona: Anagrama , 1995.

APPADURAI. La vida social de las cosas. Perspectiva cultural de las mercancías. México, DF: CNCA y Grijalbo, 1991.

BARBER, Benjamin. Consumed: How Markets Corrupt Children, Infantilize Adults and Swallow Citizens Whole. New York: Norton, 2008.

BAUDRILLARD, Jean. Crítica de la economía política del signo. México, DF: Siglo XXI, 1989.

BAUMAN, Zygmunt. Modernidad líquida. México, DF: FCE, 2000.

BELL, Daniel. Las contradicciones culturales de la modernidad. México, DF: Anthropos, 2007.

BLAKELI, Edward J.; GAIL SNYDER, Mary . Fortress America: Gated Communities in the United States. Cambridge, Massachusetts: Brooking Institution Press and Lincoln Institute of Land Policy, 1997.

BUENO CASTEllanOS, Carmen. Configuraciones productivas en la globalización. Trayectorias a la mexicana. México, DF: Universidad Iberoamericana, 2016.

CALDEIRA, Teresa. City of Walls. Crime. Segregation and Citizenship in São Paulo. California: University of California Press, 2000.

CASTELLS, Manuel. La era de la información. Economía, sociedad y cultura. México, DF: Siglo XXI, 2006.

CORONADO SUZÁN, Gabriela. Las voces silenciadas de la cultura mexicana. Identidad, resistencia y creatividad en el diálogo intrétnico. México, DF: CIESAS, 2003.

DOUGLAS, Mary. Estilos de pensar. Barcelona: Gedisa, 2008.

DOUGLAS, Mary; ISHERWOOD, Mary. El mundo de los bienes. Hacia una antropología del sonsumo. México, DF: CNCA y Grijalbo, 1990.

DAVIS, Mike. City of Quartz. Excavating the Future in Los Angeles. Londres; Nueva York: Vintage Books, 1992.

EWEN, Stuart. Todas las imágenes del consumismo. La política del estilo en la cultura contemporánea. México, DF: CNCA y Grijalbo, 1991.

GONZÁLEZ CASANOVA, Pablo. El colonialismo interno. De la sociología del poder a la sociología de la explotación: Pensar América Latina en el siglo XXI, Buenos
Aires: CLACSO, 2009. P. 129-156.

GONZÁlEZ RODRÍGUEZ, Sergio. Campo de guerra. México, DF: Anagrama, 2014.

GONZÁLEZ ORTIZ, Felipe. Multiculturalismo y metrópoli. Cultura política en un fragfmento urbano (antropología urbana). México, DF: UAM-I, 2009.

. Megalópoli y cultura. Del ritual indígena al performance urbano. México, DF: Porrúa y UAEMex, 2012.

; VALENCIA LONDOÑO, Paula. Desigualdad

horizontal y democracia con desigualdad en México y Colombia. No prelo, 2017.

HARVEY, David. El nuevo imperialismo, acumulación por desposesión. Buenos Aires: CLACSO, 2005.

HIRTH, Kenneth, G. Los mercados prehispánicos, la economía y el comercio. Arqueología mexicana, CNCA, INAH, México, v. XXI, n. 122, p. 30-37, 2013.

LEONARD, Annie. La historia de las cosas. De cómo nuestra obsesión por las cosas está destruyendo el planeta, nuestras comunidades y nuestra salud. Y una visión de cambio. Buenos Aires: FCE, 2013.

MCKENZIE, Evan. Privatopia. Homeowner Associations and Residential Private Government. Yale: Yale University Press, 1994.

MARX, Carlos. El capital. México, DF: FCE, 1986.

MERTON, Robert. Teoría y estructura sociales. México, DF: FCE, 2002.

NAVARRETE, Federico. Las relaciones interétnicas en México. México, DF: UNAM, 2004.

PARSONS, Talcott. La estructura de la accioón social. México, DF: Guadarrama, 1961.

POLANYI, Karl. El sistema económico como proceso institucionalizado.In:GODELIER,Maurice (Ed.).Antropología y economía. Barcelona: Anagrama, 1976. p. 155-178.

RAPHAEL, Ricardo. Mirreynato: la otra desigualdad. México, DF: Planeta, 2014.

SOJA, Edward. Postmetropolis. Critical Studies of Cities and Regions. Cambridge, MA: Blackwell Publishers INC, 2000 .

Thirdspace, Journeys to Los Angeles and Other Real and Imagined Places. Cambridge, MA: Blackwell Publishers INC, 1996.

STEWARD, Frances.¿Por qué persisten las desigualdades de grupo? Las trampas de la desigualdad horizontal, Disponível em: <https://es.scribd.com/document/317338685/Porque-persisten-las-desigualdades-de-grupo-pdf $>$. Acesso em: 21 jun. 2016.

TAYLOR, Charles. El multiculturalismo y la política del reconocimiento. México, DF: FCE, 1999.

TÖNNIES, Ferdinand. Comunidad y asociación. Barcelona: Península, 1979.

\section{PÁGINAS DE INTERNET CONSULTADAS:}

¿Por qué Walmart decidió cerrar 269 tiendas en todo el mundo? Disponível em: <http://www.bbc.com/mundo/ noticias/2016/01/160115_economia_walmart_cierre_ 
tiendas_estados_unidos_mundial_ppb $>$. Acesso em: 21 jun. 2016.

Escándalo por sobornos de Wal-Mart, con pocas evidencias de corrupción: WSJ. Disponível em: <http://www. elfinanciero.com.mx/empresas/escandalo-por-sobornosde-walmart-con-pocas-evidencias-de-corrupcion-wsj. html>. Acesso em: 21 jun. 2016.

Walmart, el costo a un año del escándalo. Disponível em: $\leq$ http://expansion.mx/negocios/2013/04/17/walmart-elcosto-a-un-ano-del-escandalo>. Acesso em: 21 jun. 2016. 


\section{The supermarket: a stage of trade to invent work and consumption}

\section{Abstract}

I present an analysis of work and consumption in the supermarket, place where the relationships are developed. From the trajectories of the goods and the workers I build the economic and cultural forms that define offer and demand. I approach the forms of segmentation of offer that the demand builds, the forms of mobility (trajectories) of goods in a system that is inscribed in the global and the local, and the ways of organizing labor relations to optimize the mission of this type of trade: retail sales.

Keywords: supermarket, offer and demand, mobility of goods, trajectories of persons.

\section{O supermercado: um cenário de comércio para inventar o trabalho e o}

\section{consumo}

\section{Resumo}

Analisa-se o trabalho e o consumo no supermercado, espaço ou arena onde se configuram relações. A partir dos trajetos das mercadorias e dos trabalhadores, definem-se as formas econômicas e culturais que configuram a oferta e a demanda. Abordam-se as formas de segmentação da oferta em função da demanda, as formas de mobilidade das mercadorias em um sistema que se inscreve no global e no local, e as formas singulares de organizar as relações de trabalho para otimizar a missão deste tipo de comércio: realizar vendas no varejo.

Palavas-chave: supermercado, oferta e demanda, trajetórias de bens, trajetória de pessoas.

Data de recebimento do artigo: 10/01/2017

Data de aprovação do artigo: 30/06/2017 